\title{
INTERthesis
}

\author{
RESENHA - REVIEW - RESEÑA
}

\section{CIDADES PEQUENAS: PERSPECTIVAS TEÓRICAS E TRANSFORMAÇÕES SOCIOESPACIAIS}

\section{SMALL TOWNS: THEORETICAL PERSPECTIVES AND SOCIO-SPATIAL TRANSFORMATIONS}

\section{CIUDADES PEQUEÑAS: PERSPECTIVAS TEÓRICAS Y TRANSFORMACIONES SOCIO-ESPACIALES}

SPOSITO, Eliseu Savério; SILVA, Paulo Fernando Jurado da. Cidades Pequenas: perspectivas teóricas e transformações socioespaciais. Jundiaí: Paco Editorial, 2013, $148 \mathrm{p}$.

Publicada em 2013 pela editora Paco Editorial de Jundiaí-SP, a presente obra, de autoria de Eliseu Savério Sposito e Paulo Fernando Jurado da Silva, objetiva discorrer sobre a definição de cidade pequena a partir da análise de vários trabalhos e artigos dos próprios autores, bem como de dois estudos de caso. Com uma vasta experiência científica, principalmente nas áreas de Geografia Urbana, Geografia Econômica, pensamento geográfico, industrialização, território, cidades pequenas, redes urbanas, dentre outros, com este livro os autores ajudam assim a ampliar quantitativa e qualitativamente os debates acerca do tema.

Desenvolvido em duas partes, "perspectivas teóricas" e "estudos de caso", a obra traz inicialmente quatro subtítulos: "as cidades pequenas como tema geográfico"; "os estudos sobre cidades pequenas"; "definição e conceituação: diferenciações importantes"; "urbanização, transformações socioespaciais e cidades pequenas", encerrando-se com as considerações finais. Na segunda parte, dois estudos de caso: "a região administrativa de Presidente Prudente, as cidades pequenas e a dinâmica econômica" (dividido em três pontos), de autoria de Paulo F.

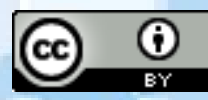

Esta obra foi licenciada com uma Licença Creative Commons - Atribuição 3.0 Não Adaptada.
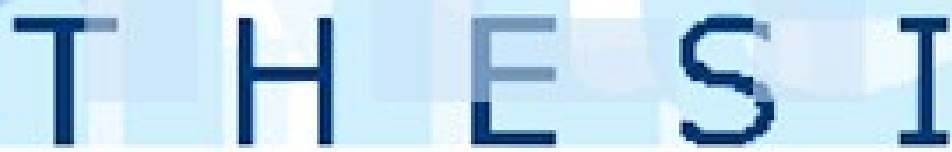
J. da Silva e "Tarabay: um centro pré-urbano do sudoeste paulista", de Eliseu S. Sposito.

O tema "cidades pequenas" vem ganhando espaço cada vez maior no cenário acadêmico, inclusive no Brasil, mas não se compara à hegemonia quantitativa da produção de textos sobre grandes aglomerações/metrópoles.

O primeiro subtítulo da primeira parte do livro consiste em um levantamento teórico acerca do tema, onde os autores afirmam que este não está acabado ou esgotado no cenário de estudos, mas em construção e transformação continua. De forma geral, a cidade pequena é apontada pelos autores como um recorte empírico/teórico do fato urbano, possuindo uma totalidade particular movida por processos capitalistas de produção. Contudo, alertam que não se deve estudá-la isoladamente, pois está inserida num processo de urbanização construída contraditoriamente pela sociedade ao longo do tempo.

O segundo subtítulo mostra que o tema "cidades pequenas" tem sido estudado por vários autores, incorporando questões sobre planejamento ambiental, reprodução social, produção de moradia, globalização, papéis e significados urbanos. É criticado ainda o uso negligenciado da ideia de "cidade pequena", com conotação vaga, em especial, pelos leigos, Estado e pela Mídia, como: cidade pacata, miserável, etc., implicando na perda de seu sentido geográfico. Portanto, segundo os autores, em seu levantamento teórico não pode haver generalizações e simplificações, propondo-se uma regra geral universal para a definição destes centros.

O livro aponta que somente no início do século XXI houve um aumento quantitativo de publicações sobre pequenas cidades no Brasil, sobretudo nas investigações de pós-graduação, e ressalta também a necessidade de se explorar qualitativamente cada vez mais a temática. Mostra ainda que a escala, nos estudos sobre pequenas cidades, deve ser a municipal, num esforço analítico de apreensão da realidade por meio de um recorte estatístico, sendo este inserido num plano maior, dentro da rede urbana, com processos de urbanização diferenciados no mundo.

O terceiro subtítulo trata da dialética entre definição e conceituação, ressaltando-se que se deve buscar, nos estudos e trabalhos científicos, um conceito cada vez mais consistente de cidade pequena, que passa também pelo conceito de

R. Inter. Interdisc. INTERthesis, Florianópolis, v.11, n.2, p.272-277, Jul-Dez. 2014
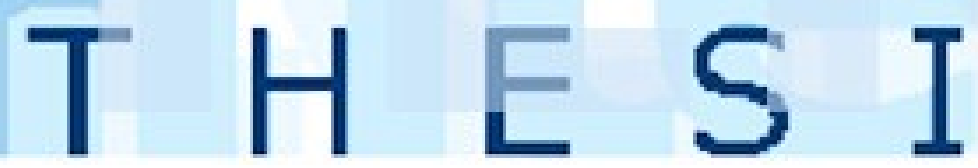
cidade. Mostra ainda a discussão e as diversas abordagens sobre o tema em vários países, cada uma com suas características próprias: física, econômica, política e cultural.

Segundo os autores, a relação campo-cidade nas cidades pequenas ganha significado especial, mas é na urbanização que se encontra o caminho para o debate das recentes transformações socioespaciais pelas quais vem passando tais centros.

Nas ciências humanas, segundo Sposito e Silva, busca-se superar a noção inicial, delimitada, fixa e exata de um determinado objeto de estudo (reduzir a cidade a uma expressão numérica, por exemplo), provinda de sua definição que, em muitos casos, possui cunho político despreocupado com os núcleos urbanos de baixo índice demográfico.

No quarto subtítulo aborda-se a dimensão qualitativa da cidade, buscando-se confrontar as relações estabelecidas no plano social/econômico e que as movem na divisão territorial do trabalho em diferentes escalas espaciais ao longo do tempo. Os autores discutem o tema da urbanização e afirmam que, sob o capitalismo, a cidade passou a ter um significado predominantemente econômico, sendo local de mercado e da comercialização de produtos diversos, da especialização funcional e, também, da desigualdade. Trazem também uma leitura sobre a teoria das localidades centrais de Walter Christaller, no que diz respeito a rede urbana, criticando, porém, essa teoria através de Roberto Lobato Corrêa, por sua inaplicabilidade aos dias atuais resultante de sua desatualização/descontextualização (se estudada/interpretada tal como fora criada, no início do século XX).

O livro retrata também as transformações ocorridas no final do século $X X$ no Brasil com o processo de industrialização/urbanização, em especial em São Paulo, e a concentração de riquezas em algumas cidades (como a capital paulista), além da formação de diversas pequenas cidades.

A primeira parte do livro encerra-se frisando que os estudos sobre cidades pequenas não estão esgotados e que tais cidades estão inseridas na rede urbana de forma cada vez mais complexa, ligadas ao capital internacional, frutos do avanço da mundialização e expansão do capital. Ressalta também a importância das telecomunicações e das informações na inserção das pequenas cidades na dinâmica do mundo globalizado.

R. Inter. Interdisc. INTERthesis, Florianópolis, v.11, n.2, p.272-277, Jul-Dez. 2014
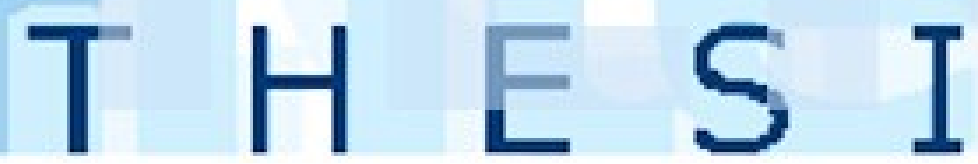
A segunda parte da obra intitulada "os estudos de caso", de autoria de Paulo Fernando Jurado da Silva, em seu primeiro ponto, objetiva analisar o sentido econômico da região administrativa de Presidente Prudente-SP e a formação das cidades pequenas na expansão urbana do século XX e início do XXI. Silva utiliza como referencial teórico os estudos de Leon Trotsky (desenvolvimento desigual e combinado), Gunnar Myrdal (causação circular e acumulativa), Karl Marx (leitura sobre capitalismo), além de outros.

O autor questiona o caráter do desenvolvimento desigual e combinado na região de Presidente Prudente a fim de compreender sua dinâmica territorial. Para tal, inicia com a problematização do conceito de desenvolvimento e decide por acatar a linguagem de Trotsky: o desenvolvimento é discutido a partir da dimensão econômica (capitalista-marxista), e sua face espacial é a adjetivação desigual e combinada, que produz sínteses e contradições sociais. Silva afirma ainda que o desenvolvimento desigual verificado no fato urbano pode revelar a ordem, o papel e a significação geográfica que os núcleos assumem historicamente no processo de urbanização.

De acordo com o autor, a disparidade na região referida é fruto de um desequilíbrio de investimentos e de drenagem de capital a determinados espaços em detrimento de outros. Daí a existência de pequenas e grandes cidades. Silva compara ainda a centralidade da capital paulista com a "menor atenção dada" (por aqueles de específica responsabilidade) à região de Presidente Prudente, afirmando que esta sofreu com o fortalecimento da outra.

Ainda no primeiro estudo de caso, em seu segundo ponto, é feito um detalhamento do perfil industrial dos municípios da região administrativa de Presidente Prudente, além dos empregos que não se resumem à indústria. Mostra ainda que esse quadro resulta da base econômica da região, em especial da inserção tardia no circuito cafeeiro paulista do século $X X$, o que reflete em seu Produto Interno Bruto (PIB). Segundo o autor, do ponto de vista administrativo, a região não deve ser vista como homogênea, mas por suas contradições e pela luta de classes historicamente construída, que transforma as relações socioespaciais.

O terceiro ponto aborda a gênese de pequenas cidades na região de Presidente Prudente pelas forças econômicas da época. Insiste também que a industrialização é um importante meio de crescimento demográfico e econômico

R. Inter. Interdisc. INTERthesis, Florianópolis, v.11, n.2, p.272-277, Jul-Dez. 2014
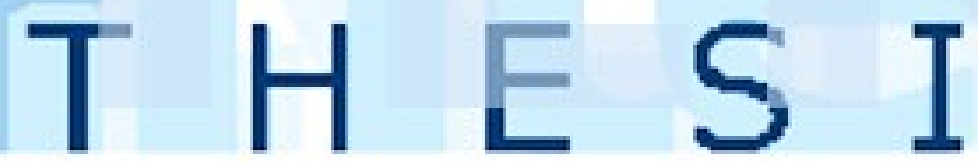
para as cidades, dando relevância ao papel da ferrovia como fator de localização das urbes e à formação de uma hierarquia e centralidade urbana na segunda metade do século XX (menciona Walter Christaller, mas pondera que essa hierarquia já não se aplica devido às evoluções tecnocientíficas)

O autor finaliza o primeiro estudo de caso com as redes, mostrando que, ao serem produzidas, conformam desigualdades no sentido espacial, por seus pontos de comunicação não serem iguais, competindo para o acirramento destas desigualdades.

Por fim, o segundo estudo de caso, de autoria de Eliseu Savério Sposito, aborda Tarabay, um centro pré-urbano do sudoeste paulista de população oriunda do meio agrícola. Neste estudo são assinalados os fatores que barraram o crescimento da cidade. De início, o autor caracteriza a cidade em três fases: a primeira, com seu surgimento a partir das migrações de nordestinos, mineiros e japoneses pelo café; a segunda, com o crescimento da cidade pela construção de ruas, avenidas, casas, etc., na tentativa de fixação da população, e a terceira, caracterizada por seu declínio em todos os sentidos, em especial pela migração em busca de trabalho (nas indústrias, principalmente) e pela concorrência com Presidente Prudente e Pirapozinho, o que provocou a estagnação (crescimento e desenvolvimento) de Tarabay..

Sposito segue fazendo caracterizações da cidade, desde os aspectos demográficos e de moradia à atividade/trabalho, este último focado nos boias-frias. $\mathrm{O}$ autor conclui afirmando que Tarabay possui traços nordestinos, oriundos das migrações em sua gênese e que se configura como um centro de emigração e moradia de pessoas que se locomovem diariamente para o campo.

De forma geral, o presente livro apresenta um conjunto de estudos sobre a pequena cidade, mostrando diversos conceitos, sua dinâmica, seu desenvolvimento e sua representatividade no cenário capitalista global, justificando o investimento em tais estudos. Critica ainda o uso negligenciado e vago do conceito de pequena cidade por leigos e pela mídia, desvalorizando-a em meio à hegemonia quantitativa de produções/trabalhos sobre aglomerações/metrópoles. É criticada também a valorização de determinadas cidades (do grande capital) em detrimento de outras (principalmente pequenas cidades), no decorrer da formação espacial do país,

R. Inter. Interdisc. INTERthesis, Florianópolis, v.11, n.2, p.272-277, Jul-Dez. 2014
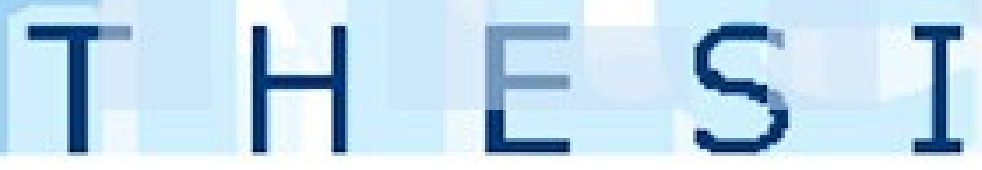
promovendo o enfraquecimento destas tanto na economia quanto em seu desenvolvimento, resultando muitas vezes no desaparecimento de tais cidades.

Em suma, com este livro, além de outros trabalhos, os autores contribuem para o enriquecimento científico acerca das cidades pequenas e, portanto, para a construção do conhecimento sobre este temário, o que poderá auxiliar na elaboração de outras obras e discussões.

Por:

Francisco John Lennon Alves Paixão Lima, Mestrando em Geografia pela Universidade Estadual de Maringá, Maringá, PR, Brasil. E-mail: johnlima ce@yahoo.com.br

Maria das Graças de Lima, doutora em Geografia (Geografia Humana) pela Universidade de São Paulo, e Estágio Pós-doutoral pela Universidade de São Paulo. Professora Associada do Departamento de Geografia da Universidade Estadual de Maringá, Maringá, PR, Brasil. E-mail: mglima@uem.br

\section{Resenha:}

Recebido em Agosto de 2014 Aceito em Outubro de 2014

R. Inter. Interdisc. INTERthesis, Florianópolis, v.11, n.2, p.272-277, Jul-Dez. 2014 